\title{
Development and psychometric assessment of the sexual health education necessity scale: An exploratory mixed method study
}

\author{
Azam Rahmani ${ }^{1}$, Vinnaras Nithyanantham ${ }^{2}$, Arezoo Fallahi $^{3}$, Leila Allahqoli*4, Narges Sadeghi ${ }^{5}$
}

Received: 24 Jun 2018

Published: 7 Sep 2019

\begin{abstract}
Background: Sexual health education is a controversial issue within the Iranian context. Thus, the present study was conducted to explore the necessity of sex education among young single women and develop and examine the psychometric properties of the Sexual Health Education Necessity Scale.

Methods: This was an exploratory mixed method study. Young single women (51 women in the first phase and 110 women in the second phase of the study) aged 18-34 years were recruited in the study. In the first phase, qualitative methods were applied to generate items. In the second phase, psychometric properties, such as face, content, and construct validity, and reliability of the Sexual Health Education Necessity Scale were evaluated. In the first phase, an item pool was developed that included 17 statements related to sexual health education necessity. In the second phase, item reduction was applied using exploratory factor analysis and the final version of the questionnaire containing 9 items was developed. Also, content, face, and construct validity were assessed. Moreover, Cronbach's alpha coefficient and test-retest were calculated to evaluate the reliability of the questionnaire. SPSS software (version 21) was used for data analysis and $\mathrm{p}$ value less than 0.05 was considered as significant.

Results: In the qualitative phase, 4 key themes emerged regarding sex education, which included the effects of sex education, principles of sex education, content of sex education, and organizations responsible for sex education. An item pool containing 17 statements was generated and used for psychometric evaluation. The results of the exploratory factor analysis showed a 2-factor solution for the scale, which collectively accounted for the $56.04 \%$ of the variance. Final CVR and CVI were found to be 0.96 and 0.97 , respectively. The Cronbach's alpha coefficient and test-retest of the instrument was found to be 0.78 and 0.80 , respectively.

Conclusion: Sexual Health Education Necessity Scale can be used for exploring dominant beliefs that may be obstacles for providing sex education in conservative societies; therefore, correcting these beliefs could help to design an appropriate sexual health education program.
\end{abstract}

Keywords: Psychometric evaluation, Sexual health education, Young single women, Exploratory mixed method

Conflicts of Interest: None declared

Funding: Tarbiat Modares University has funded this project.

*This work has been published under CC BY-NC-SA 1.0 license.

Copyright $\odot$ Iran University of Medical Sciences

Cite this article as: Rahmani A, Nithyanantham V, Fallahi A, Allahqoli L, Sadeghi N. Development and psychometric assessment of the sexual health education necessity scale: An exploratory mixed method study. Med J Islam Repub Iran. 2019 (7 Sep);33:94. https://doi.org/10.47176/mjiri.33.94

Corresponding author: Dr Leila Allahqoli, allahqoli.l@iums.ac.ir

1. Nursing and Midwifery Care Research Center, School of Nursing and Midwifery, Tehran University of Medical Sciences, Tehran, Iran

2. Department of General Education, College of Education and Languages, Lebanese French University, Erbil, Kurdistan, Iraq

3. Social Determinants of Health Research Center, Research Institute for Health Development, Kurdistan University of Medical Sciences, Sanandaj, Iran

4. Endometriosis Research Center, Iran University of Medical Sciences, Tehran, Iran

5. Department of Nursing, Community Health Research Center, Isfahan (Khorasgan) Branch, Islamic Azad University, Isfahan, Iran 个hat is "already known” in this topic:

Sexual health education has been remained controversial within the Iranian context because of broad cultural and religious beliefs. Programs that negate conventional teachings and do not endeavor to attain some level of acknowledgment of power holders within the community are likely to fall flat. Thus, success in sexual health education depends on community agreement. However, the necessity of sex education in the Iranian context has not been addressed.

\section{$\rightarrow$ What this article adds:}

Most (more than $70 \%$ ) of Iranian young women believed that sex education could be useful for them. Sociocultural considerations were highlighted in their statements. The findings of this study provided a primary prove for psychometric properties of the Sexual Health Education Necessity Scale. Scientific documents could convince health care providers and policymakers to consider sexual health education as a necessity for the Iranian society. 


\section{Introduction}

In spite of the fact that the significance of sex education for adolescents is well known in different societies (1), it has been remained controversial within the Iranian context; this controversy stems from cultural and religious assumptions of abstinence. Within the Iranian context, similar to other Muslim societies (2), any premarital sexual relationship is religiously, socially, and legally forbidden (3). In addition, numerous individuals with particular ethical views are worried that adolescents will engage in sexual activities as a consequence of sex education (4).

Some private schools within the Iranian context integrated reproductive health and HIV prevention into the health education curriculum (5). Also, in 1993, a family planning course was introduced into most Iranian universities to provide general issues, such as reproduction, male and female reproductive system, contraceptive methods, and population policy, but these courses were not comprehensive enough (5). Despite the vast progress in public health education at the national level within the Iranian context, there is no comprehensive program of sex education for children, adolescents, or adults (6). Comprehensive sex education considers all people as sexual beings and covers a broad range of issues relating to biological, social, and emotional aspects of sexuality. This education considers the age and level of development of the target group (7).

Providing sex education is fundamental within the Iranian context, like other societies, for several reasons. Young people make up around $20 \%$ of the Iranian population (8). There are different definitions for adolescent years around the world: 10-24 (9), 15-24 (10), or 18-34 (11) years. This group tend to postpone their marriage, the only institution that legally allows them to have sexual behaviors. In any case, in spite of the law, about $50 \%$ of adolescents begin their sexual behaviors before marriage (3). A study that was conducted on 1385 Iranian male adolescents (15-18 years) in Tehran showed that young people engaged in their first sexual coitus at age 15, and $68.2 \%$ of them who were sexually active experienced at least one of sexual risk-taking behaviors (12). Also, engaging in sexual risk-taking behaviors, including unprotected sexual intercourse and multiple sexual partner, is the second major cause of HIV transmission within the Iranian context $(13,14)$.

Although there is no sexual health education within the Iranian context, a new sexual health education program could not simply be plugged into the curriculum because there are broad cultural and religious beliefs related to sex education. Therefore, attitudes and concerns of youths need to be considered to design a culturally appropriate sex education (15). Although there was no formal and curricular-based sex education in the Iranian schools, some of the young single women received sex education from their family or teachers. The present study, which focused on both women who have received and have not received sex education, could be very helpful in reflecting whether sexual health education is essential, useful, or unnecessary for the Iranian youths.
Globally, there are many studies focusing on sexual health education in schools (16-18) and universities (19, 20 ), but few studies have been conducted about sex education within the Iranian context $(21,22)$. Although few studies have aimed to scale development on sexual health education necessity, a study on 130 mothers in school children in Ontario, Canada, found that most mothers had supportive beliefs regarding sex education but they did not know which values are more appropriate for teaching. While more than half of them did not approve premarital sexual behaviors, merely one-third believed that an imperative objective of sex education ought to be to debilitate premarital sexual behaviors (23). Another study was conducted in Tanzania to evaluate suitability of parents of teenagers towards sexual and reproductive health education within schools and community. Parents believed that they ought to have conversation with their teenagers regarding reproductive health and sexuality $(88.6 \%)$, but their culture has forbidden them from doing so $(76.7 \%)$. In addition, they confirmed that condoms could be a protective tool against HIV/AIDS and STIs (82\%), but they emphatically restricted condom use to their teenagers since they believed it would energize promiscuity (78\%). Also, they believed that the favored source of data regarding sex education should be from the parents $(86 \%)$, devout pioneers $(70 \%)$, media $(62 \%)$, specialists $(61 \%)$, and school instructors (59\%) (24). In Iran, a study was developed to investigate the perspectives and encounters of teenage girls and key grown-ups about the need to provide reproductive and sexual health information and services for teenage girls in Iran. The current study has reported 6 main reasons for the need to provide reproductive and sexual health services for teenager ladies: 1) an absence of satisfactory learning about reproductive and sexual health, 2) simple access to incorrect data sources, 3) social and cultural changes, 4) expanding risk-taking sexual behaviors among teenagers, 5) religion's accentuation on sex education of teenagers and youths, and 6) the presence of social taboos (25).

However, older members of the family, community, and policymakers are frequently confused and concerned about sexual behaviors, lifestyles, and sexual health education of the youths (26). Experience has demonstrated that programs that negate conventional teachings and do not endeavor to attain some level of acknowledgment of power holders within the community are likely to fall flat (27). Prosperity in sexual health education is more probable when the society agrees and selects to change its customs itself (28).

Since sexual health education has remained controversial within the Iranian context and a new sexual health education program could not simply be plugged into the curriculum because of the broad cultural and religious beliefs, providing scientific documents could convince health care providers and policymakers to consider sexual health education as a necessity of the Iranian society. The aim of the present study was to explore the necessity of sex education and develop and examine the psychometric 
properties of a Sexual Health Education Necessity Scale.

\section{Methods}

This was an exploratory mixed method study which was performed in 2 steps in 2015. In the first step, generating items and developing the questionnaire was done using a qualitative approach, and in the next phase, reliability and validity of the scale were evaluated (29).

\section{Phase 1: Item generation and scale development}

In this phase, focus group discussions (FGDs) and individual indepth interviews were applied to develop a sexual health education necessity scale. Also, young single women $(\mathrm{n}=51)$ aged $18-34$ years were selected. There are different definitions for youths around the world. Since the purpose of this study was to cover a broader age range, the definition provided by the National Youth Organization was selected. This organization considers the age range of 18-34 years as young (11). In this study, this age group was selected because some of this generation received sex education and others did not. Therefore, this age group could help us more appropriately to assess different views and possible outcomes about receiving or not receiving sex education. In addition, this age group might engage in sexual experiences and could better talk about sex education for youths considering their own experience. In the first step, it was planned to conduct research on both girls and boys, but the ethics committee did not approve working on male participants, because the primary researcher in this study was a female and applying cross-sex interview on such a sensitive issue was not acceptable within the Iranian context. After finding about the difficulty of having cross-gendered interviews in the Iranian culture, the authors agreed that it would be appropriate to have a male research assistant to cover the gap of cross-gendered interviews; and in such a case, these 2 researchers had to analyze the data through close interaction to reach a common understanding about each session and interview. However, the ethic committee did not approve it. The justification of the committee was that close interaction between the cross-gendered researchers was not appropriate in the Iranian context because of some cultural and ethical considerations.

Focus group discussion was performed as the primary means of data collection. Perposive sampling was used to approach the participants in different dormitories regardless of recieving sex education and engaging in sexual behaviors. A total of 7 young single women participated in each FGD. Informed written consent was obtained from the participants. The sessions were simplified by describing sex education and using a nonstructured inventory that began with the open-ended questions: 'Have you ever received sexual and reproductive health education?' and 'How do you think the youths should obtain sexuality-related information?' Afterwards, based on the responses, subsequent questions were built and continued. Some other questions of the interviews included, 'Which content did you receive about sexuality?', 'Who have educated you regarding sexual health?',
'Do you think sex education is necessary in the Iranian context?', 'What are advantages and disadvantages of sex education?', and 'Who or which organization is responsible for sex education?'

In the FGDs, participants with different views, values, and encounters discussed the cultural aspect of sex education. In this phase, data were produced by prevailing social standards.

Potential informants for individual interviews were identified during FGDs (4 young single women). Also, snowball sampling was applied to approach other young single women who engaged in premarital sexual behaviors (8 young single women). In fact, the social aspects of sex education were discussed in FGDs and private experiences of single young women were explored in individual indepth interviews. In spite of the fact that ladies who had premarital sexual experience did not talk directly about their sexual experience in the discussions, they were distinguished when they talked about their viewpoints regarding sex education and sexual behaviors.

Maximum variation sampling (different age groups, different educational levels, different socioeconomic backgrounds, and high and low levels of religiosity) was continued to achive greater transferability of data (30). Most particippants lived in dorms and some of them lived with their families. Twelve individual interviewes and 6 focus group discussions were held. Data were saturated aftrer 11 individual interviews and 5 focus group discussions (31).

Also, Graneheim and Lundman's approach was used to analyize the qualitative data (32). Each focus group discussion or individual in-depth interview was done before the next interview or discussion. Thorough comprehension of the data was achived by reading and rereading. Aftwrwards, the units of meanings were extracted and were coded line-by-line; finally, categories and themes were made dependent on the comparative codes. There was a specialist second coder in the investigation, and 5 participants were asked to have a glance on the summary of the findings (member check); likewise, substantive codes and themes were checked by 3 expert individuals (peer check) (33). Applying numerous techniques for data gathering (eg, focus group discussion and individual in-depth interview) could enhance dependability and credibility of data (30).

Phase 2: Psychometric evaluation of the Sexual Health Education Necessity Scale

The first draft of the questionnaire was developed based on the findings extracted from the qualitative phase. The prefinal draft of the Sexual Health Education Necessity Scale contained 17 items and every item was evaluated on a 5-point response scale (completely disagree to completely agree).

Face, content, and construct validity were assessed; also Cronbach's alpha coefficient and test-retest were calculated to evaluate the reliability of the questionnaire.

Quantitative and qualitative methods were used to assess content validity. An expert panel, including 10 experts who specialized in sexuality and psychometric 
evaluation, assessed the content validity of the questionnaire. Grammar, wording, scaling, and item allocation of the questionnaire were evaluated to assess qualitative validity (34). Also, the content validity ratio (CVR) and the content validity index (CVI) were computed in quantitative assessment.

Lucidity, straightforwardness, and pertinence of every item were evaluated by CVI assessment. Also, a Likerttype and ordinal scale with 4 potential replies were used to evauate the CVI. The replies contained a rating from 1 (not related, not straightforward, and not obvious) to 4 (very related, very straightforward, and extremely obvious) (35). The CVI was determined based on the proportion of items that got a rating of 3 or 4 by the specialists. Moreover, the essentiality of the items were assessed by computing the CVR; in fact, the experts rated each item as not essential, useful but not essential, or essential, (36). In the quantitative phase of content validity, items with CVR and CVI under 62 and 80 were deleted, respectively (36).

Qualitative and quantitative procedures were used to evaluate face validity. In the qualitative phase, 10 young single women were asked to evaluate the questionnaire and demonstrate hardness or equivocation in responding the questionnaire. In the quantitative stage, the impact score showed the level of single young women who distinguished the items as significant or very significant. Items with impact score equivalent or more than 1.5 were viewed as appropriate, corresponding to a mean recurrence of half and a mean significance of 3 on the 5point Likert scale (37). Impact score was calculated to examine quantitative face validity. Impact scores of the items ranged from 1.2 to 5 (37).

Young single women aged 18-34 years who lived in dormitories were recruited. Sample size based on the quantity of items in the scale was increased by 10 (7). Thus, a sample of 90 young single women was considered. Due to the risk of incomplete questionnaires, 110 young single women were approached. After obtaining informed written consent, participants completed the questionnaires using convinence sampling method. Moreover, exploratory factor analysis (EFA) was performed to explore the latent constructs of the scale. A principle component analysis (PCA) with varimax rotation was applied and the factor loading equal or greater than 0.4 was considered as acceptable (7).

The Cronbach's alpha coefficient was calculated to evaluate the internal consistency of the scale. Values equivalent or more than 0.70 were considered as acceptable (38). Also, test-retest reliability was conducted to assess the questionnaire's stability. A total of 30 participants were asked to complete the questionnaire twice with a 2week interval (39).

Confirmation to lead the examination was approved by the Ethics Committee of the Faculty of Medicine of Tarbiat Modares University, Tehran, Iran. Participants were guaranteed that taking part in the study was optional and their privacy and identity would remain anonymous. Informed written consent was obtained from all participants.

\section{Results}

Phase 1: Item generation and scale development

In this phase, 51 young single women aged 18-34 years were recruited in the study. Baseline characteristics of the participants are shown in Table 1.

In the qualitative phase, 4 key themes emerged regarding sex education. Key themes included impacts of sexual health education, standards of sexual health education, content of sexual health education, and associations responsible for sexual health education. The framework (quotations, codes, and subthemes) is demonstrated in Table 2.

Finally, an item pool containing 17 items was generated; this version of the questionnaire was applied for psychometric assessment.

\section{Phase 2: Psychometric evaluation of the Sexual Health}

\section{Education Necessity Scale}

In total, 109 young single women completed the second phase of the study. The mean age of the participants was $24.3 \pm 3.2$ years; and most of them $(68.8 \%)$ lived in dorms. Details of baseline characteristics of participants are demonstrated in Table 3.

\section{Validity}

Five items were deleted in quantitative content validity. Final CVR and CVI were found to be 0.96 and 0.97 , respectively. In the qualitative assessment of content validity, some criteria were edited, eg, item allocation, wording, and grammar based on the experts' viewpoints.

In quantitative face validity, 3 items with values less than 1.5 were omitted and 9 items were maintaind for the next phases of psychometric evaluation. In the qualitative phase of face validity, participants reported having no difficulties in understanding and reading the items.

Also, exploratory factor analysis (EFA) was used to assess construct validity of the scale. The Kaiser-MeyerOlkin (KMO) and Bartlett's test showed that the data were appropriate for conducting factor analysis (KMO in$\mathrm{dex}=0.80, \mathrm{p}<0.001)$. Principal component analysis with varimax rotation recognized 2 components with eigenval-

Table 1. Baseline characteristics of the participants (qualitative phase)

\begin{tabular}{llcc}
\hline Variable & & No & Percent \\
& & N=51) & \\
\hline Job & Student & 24 & 47 \\
& Employed & 11 & 21.4 \\
& Unemployed & 16 & 31.5 \\
Living place & & & \\
& Dormitory & 29 & 56.8 \\
Level of Educa- & With family & 22 & 43.2 \\
tion & & & \\
& & & \\
& Diploma & 11 & 21.5 \\
& Bachelor & 19 & 37.1 \\
& Master & 16 & 31.5 \\
Economic status & Doctorate and above & 5 & 9.8 \\
& & & \\
& Poor & 8 & 15.6 \\
& Moderate & 32 & 62.7 \\
& Good & 11 & 21.5 \\
\hline
\end{tabular}


Table 2. Themes and subthemes identified in the qualitative phase (phase 1)

\begin{tabular}{|c|c|c|c|}
\hline Themes & Subthemes & Codes & Quotation \\
\hline \multirow[t]{3}{*}{$\begin{array}{l}\text { The effect of sexual } \\
\text { health education }\end{array}$} & $\begin{array}{l}\text { Advantages of sexual } \\
\text { health education }\end{array}$ & $\begin{array}{l}\text { Improvement of sexual self- } \\
\text { efficacy }\end{array}$ & $\begin{array}{l}\text { 'You know, it [sex education] will help people to think that } \\
\text { sexuality is natural and it is necessary for everyone... it } \\
\text { [sexuality] should be accepted as a reality' (FGD3) } \\
\text { 'In my opinion, it is not time to say sexuality is dirty! It is } \\
\text { better to say how to use the condom or suggest it to your } \\
\text { partner. When I wanted to have sex with my first boyfriend, } \\
\text { it was difficult for me to suggest using the condom to him. I } \\
\text { thought if I suggest using condoms, he would think I have } \\
\text { doubt about his health or I have a sexually transmitted } \\
\text { infection; then, I preferred not to say anything about it.' } \\
\text { (ind.inw5) }\end{array}$ \\
\hline & \multirow[t]{2}{*}{$\begin{array}{l}\text { Disadvantages of sexual } \\
\text { health education }\end{array}$} & $\begin{array}{l}\text { Motive for initiating sexual } \\
\text { behaviors }\end{array}$ & $\begin{array}{l}\text { 'When a person is prone to initiate her sexual relationships, } \\
\text { receiving sexual information will make her thirsty for more } \\
\text { information and motivate her for initiating sexual relation- } \\
\text { ship' (FGD1). }\end{array}$ \\
\hline & & Tainted modesty & $\begin{array}{l}\text { 'One of my relatives educated her daughter about boy- } \\
\text { friends and girlfriends. I told her that sex education is } \\
\text { wrong and may lead to break boundaries and taint modesty' } \\
\text { (FGD4). }\end{array}$ \\
\hline \multirow[t]{6}{*}{$\begin{array}{l}\text { Principles of sexual } \\
\text { health education }\end{array}$} & \multirow[t]{3}{*}{ Cultural considerations } & Dignity preservation & $\begin{array}{l}\text { 'In my opinion, dignity must be preserved and promiscuity } \\
\text { should not propagate in sex education. Premarital sex is not }\end{array}$ \\
\hline & & Prevent of promiscuity & $\begin{array}{l}\text { acceptable within the Iranian context; this point should be } \\
\text { highlighted and people know that such a relationship could }\end{array}$ \\
\hline & & $\begin{array}{l}\text { Especial consequences of } \\
\text { premarital sex }\end{array}$ & have especial consequences (FGD2).' \\
\hline & $\begin{array}{l}\text { Sexual health education as } \\
\text { a process }\end{array}$ & $\begin{array}{l}\text { Sex education based on de- } \\
\text { velopment and need }\end{array}$ & $\begin{array}{l}\text { 'Since individual development is a process, education must } \\
\text { be a process too. Sexual health education should be based } \\
\text { on people's need and development (FGD3).' }\end{array}$ \\
\hline & \multirow[t]{2}{*}{$\begin{array}{l}\text { Sexual health education by } \\
\text { valid people }\end{array}$} & $\begin{array}{l}\text { Peer education is not ac- } \\
\text { ceptable }\end{array}$ & $\begin{array}{l}\text { 'I think that sex education should be taught to youth by a } \\
\text { reliable person. It is not acceptable that adolescents receive } \\
\text { sexual information through peers. For example, a teacher }\end{array}$ \\
\hline & & $\begin{array}{l}\text { Expert teacher as an appro- } \\
\text { priate person }\end{array}$ & $\begin{array}{l}\text { who is expert in this field could be a good option. When } \\
\text { you receive information from a credible person, you may } \\
\text { react more appropriately (FGD5)'. }\end{array}$ \\
\hline \multirow[t]{6}{*}{ Educational content } & $\begin{array}{l}\text { Sexual and reproductive } \\
\text { physiology }\end{array}$ & $\begin{array}{l}\text { Genitalia as important and } \\
\text { missed issue }\end{array}$ & $\begin{array}{l}\text { 'Genitalia are important issue to be addressed in sexual } \\
\text { health education. In elementary school, we received educa- } \\
\text { tion about all parts of our body other than genitalia; that is } \\
\text { why we did not know much about our genitalia (Ind.int3)'. }\end{array}$ \\
\hline & $\begin{array}{l}\text { Avoidance of risky sexual } \\
\text { behaviors }\end{array}$ & $\begin{array}{l}\text { Safe sex as an important } \\
\text { issue }\end{array}$ & $\begin{array}{l}\text { 'It is not time to say do not engage in sexual behaviors! It is } \\
\text { better to say how to have safe and protective sexual behav- } \\
\text { iors. I mean safety of sexual behaviors is more important } \\
\text { than engaging or not-engaging in sexual activities } \\
\text { (Ind.int8)'. }\end{array}$ \\
\hline & Enrichment of sexual life & $\begin{array}{l}\text { Providing sexual education } \\
\text { for spouses: }\end{array}$ & $\begin{array}{l}\text { 'In my opinion, the solution for preventing sexual damage } \\
\text { is providing sexual education for spouses. A woman should }\end{array}$ \\
\hline & & Male body & know about male body and sexual response in both sexes. I \\
\hline & & - $\quad$ Sexual response & mean I need to know what happen in a sexual relationship \\
\hline & & $\begin{array}{l}\text { Needs of my husband } \\
\text { Sexual problems as a cause }\end{array}$ & $\begin{array}{l}\text { and what the needs of my husband to meet are. Sexual } \\
\text { problems are responsible for increased percentage of di- }\end{array}$ \\
\hline
\end{tabular}

ues more than 1.5 and factor loading equivalent or more than 0.4 , representing $56.04 \%$ of the variance. The factor loadings were as follow:

- Factor 1: Principals of sex education, with 6 items, 1-

6.

- Factor 2: Effects of sex education, with 3 items, 7-9.

The final 9-item of the scale (Table 4) contained 2 subscales such as principals and effects of sex education. Items in 'principals of sex education' subscale contained 6 questions about source, content, and quality of sexual health education and the role of policymakers and organizations in sexual health education. Since these items mostly focused on participants of sex education, this name was selected for this subscale. Also, there were 3 items on 'effects of sex education' subscale that mostly reflected the outcomes of sexual health education, such as proper decisionmaking in sexual encounters, appropriate understanding regarding sexuality, and reduction in taboo burden of sexuality in the society. The results are shown in Table 5.

\section{Reliability}

Internal consistency was applied to assess the reliability of the questionnaire. The Cronbach's alpha coefficient for the scale was 0.78 , above the acceptable threshold. In addition, the result of test-retest for the scale was 0.80 (good to excellent), which supports the stability of the scale (Fig. 1).

\section{Discussion}

The findings of this study indicated that most (more than $70 \%$ ) of Iranian women supported sex education and believed that sex education could be useful for them, as it could increase their knowledge, improve their selfefficacy, and normalize the sexuality issues. Having sexual knowledge was viewed as a tool to empower young single women to manage their sexual activities appropriately. They believed that sexuality-related 


\begin{tabular}{|c|c|c|c|}
\hline Themes & Subthemes & Codes & Quotation \\
\hline \multirow[t]{4}{*}{$\begin{array}{l}\text { Educational institu- } \\
\text { tions }\end{array}$} & Family & $\begin{array}{l}\text { Mother-daughter sex com- } \\
\text { munication } \\
\text { Avoiding sex communication } \\
\text { in family } \\
\text { Family as the first line of sex } \\
\text { education }\end{array}$ & $\begin{array}{l}\text { 'I speak about sexuality with my mother. I receive } \\
\text { sexual information I need from her. I remember that I } \\
\text { had a married friend that her mother had not spoken } \\
\text { with her about sexual relationship at all. Her mother } \\
\text { did not think that her daughter needs sexual infor- } \\
\text { mation before marriage. I think sex education should } \\
\text { start from families, especially mothers (FGD3)'. }\end{array}$ \\
\hline & School & $\begin{array}{l}\text { Receiving sex education } \\
\text { from schools } \\
\text { Necessity of plugging sex } \\
\text { education in curriculum }\end{array}$ & $\begin{array}{l}\text { 'We all are saying that we received some sexual in- } \\
\text { formation from our schools. Sexuality is very wide } \\
\text { and this education could be plugged in curriculum in } \\
\text { schools and universities. Why we could not receive } \\
\text { sex education in our schools (FGD2)'. }\end{array}$ \\
\hline & Government & $\begin{array}{l}\text { Policy makers as responsible } \\
\text { for design a culturally ap- } \\
\text { propriate sex education }\end{array}$ & $\begin{array}{l}\text { 'The problem is that people who are policy maker and } \\
\text { responsible for education should accept that it is an } \\
\text { inalienable right for people to receive sex education. It } \\
\text { is possible that they plan a socially and culturally } \\
\text { appropriate sex education (FGD6)'. }\end{array}$ \\
\hline & Media & $\begin{array}{l}\text { Media as the best means for } \\
\text { sex education in all ages: } \\
-\quad \text { TV cartoons } \\
-\quad \text { TV movies }\end{array}$ & $\begin{array}{l}\text { 'Media is the best means for education. Now, how } \\
\text { many TV movies are there for addressing sexuality } \\
\text { issues? I think TV cartoons and movies should teach } \\
\text { sexual health to kids, adolescents, youth, and families } \\
\text { (FGD1)'. }\end{array}$ \\
\hline
\end{tabular}

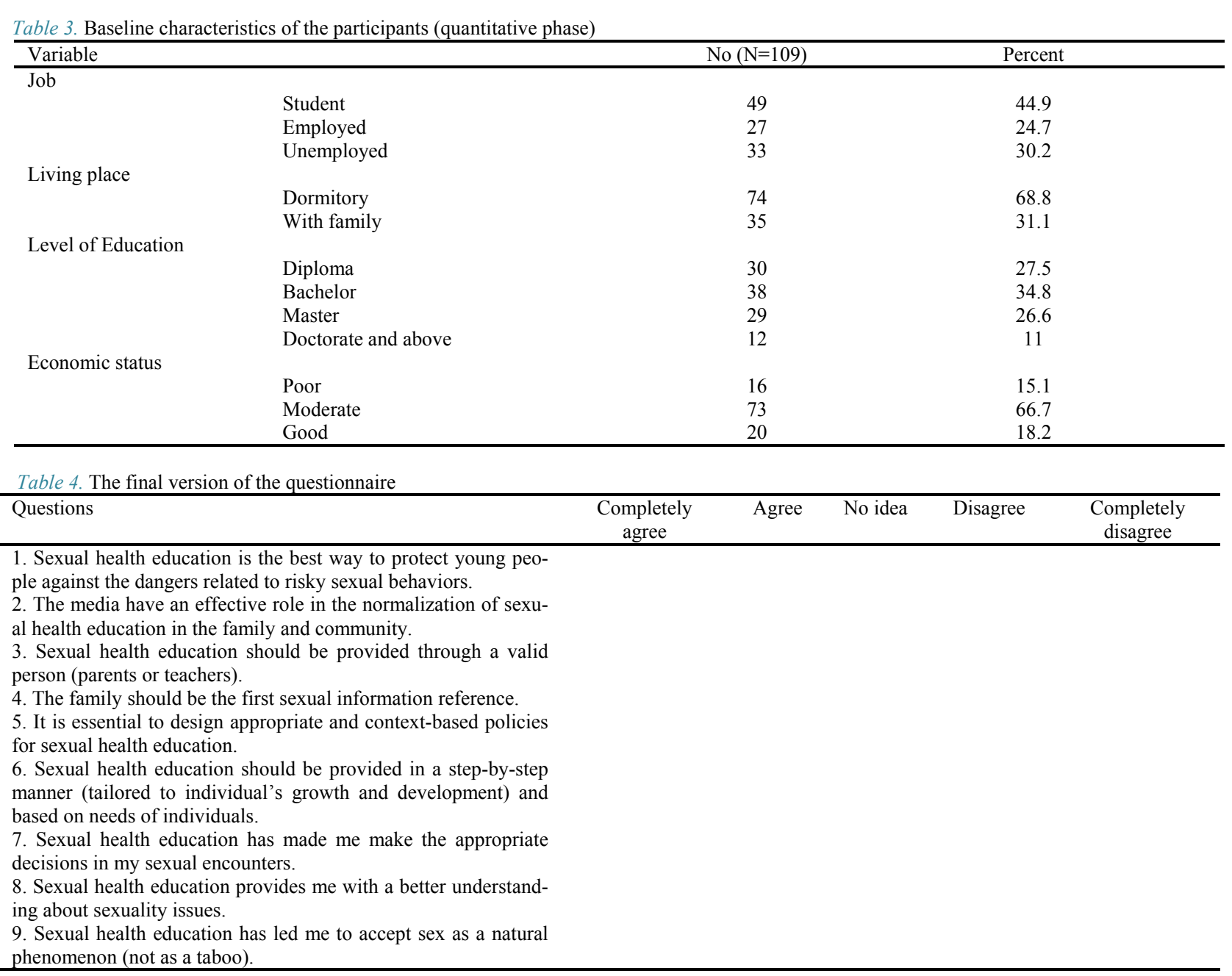

knowledge could be beneficial in several ways: learning how to have safe sex, how to protect themselves, and how to say no in their sexual encounters. The results of this study are similar to other studies that consider sex education as a means for empowering sexual self-efficacy (40-42).
The results of the present study showed that the Sexual Health Education Necessity Scale has acceptable validity and reliability. Indeed, the CVR and the CVI showed a logical content validity and the Cronbach's alpha coefficient and the result of test-retest were satisfactory and illustrated satisfactory stability and reliability for the 


\begin{tabular}{ccc} 
Table 5. Exploratory factory analysis of the scale \\
\hline Item & Factor 1 & Factor 2 \\
\hline 1 & 0.518 & 0.354 \\
2 & 0.705 & 0.071 \\
3 & 0.793 & 0.057 \\
4 & 0.598 & -0.060 \\
5 & 0.714 & 0.391 \\
6 & 0.609 & 0.275 \\
7 & 0.203 & 0.821 \\
8 & 0.321 & 0.756 \\
9 & -0.114 & 0.802 \\
\hline
\end{tabular}

Numbers in bold are related to factors loaded equal to or greater than 0.4

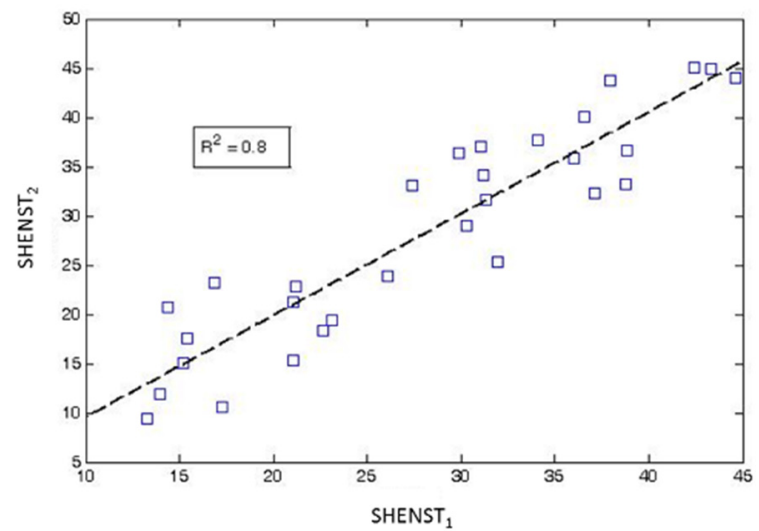

Fig. 1. Scatter plot shows the relationship between test-retest Pearson's Coefficient $(\mathrm{r}=0.8)$. Sexual Health Education Necessity scale (SHENS) $\mathrm{T} 1$ is the test value of the total SHENS score and SHENST2 is the retest value of the total SHENS score.

scale. Sexual Health Education Necessity Scale contained 2 domains (principals and effects of sex education) and 9 questions. Items in the 'effects of sex education' subscale encompassed the effects of sexual health education. In the qualitative phase, the effects of sexual health education included both benefits and negative effects of sexual health education, but items related to negative effects of sexual health education were deleted in the process of validity assessment. The possible reason for this deletion is that the majority of young single women believed that sexual health education had positive effects and a few of them reported negative effects for sexual health education.

Although most (more than $80 \%$ ) participants did not receive sexual education or were completely unfamiliar with the concept of comprehensive sex education, the principals that they stated for sex education were largely based on the principles of comprehensive sex education (43). The participants believed that sexual education should be provided by credible persons, based on the needs of individuals and according to the cultural considerations of each context.

One of the principles that participants stated was that sex education should be according to the cultural context. They believed that along with sexual education, sexual abstinence should be taught to Iranian adolescents. They stated that other countries provide sexual education to children, adolescents, and young people, while sexual behavior may be acceptable in their context; therefore, there is no need to recommend sexual abstinence in those contexts. They stated that the formula is reverse in Iran; In fact, there is no sexual education and adolescents are merely forbidden from sexual behaviors.

Participants believed that policymakers in the country do not intend or cannot accept that formal education is one of the essential requirements in the society. They stated that policymakers do not have a proper view regarding sexual education in an Islamic context. They believed that the policymakers think that sexual education is in contrast to the Islamic principles, while Islam emphasizes education in all fields, such as sexual health (2). Similarly, a qualitative study conducted by Latif Nejad et al. (2013) on the challenges of sexual education among adolescents in Iran suggested that the lack of legal support is one of the challenges of sexual education in Iran (22).

Participants stated that social and cultural structure of Iranian context is another obstacle for providing sexual education. Some of them believed that sexual education could not fit into Iranian culture because most of Iranian families consider sexual education as ugly and discredited subject; therefore, parents do not agree with formal sexual education in schools because they think that this education is not suitable for their children and they do not need sex education. A study outlined denial of premarriage sexual behaviors, perceived shame and humiliation, cultural concern regarding negative effects of sexual health education, hesitance to talk about sexual issues in public, sexual conversation as a sociocultural taboo, and imitating nonIslamic patterns of education as cultural issues related to lack of sex education in Iran (22).

Unlike Iran, some Islamic countries, such as Pakistan, Afghanistan, Bangladesh, Malaysia, and India have formal sexual education programs in their schools that cover HIV and AIDS, contraception, reproductive health, and sexually transmitted diseases (5). Although Iran has a large percentage (98\%) of Muslims and sexual abstinence is the expected behavior before marriage (44), it seems that the main reason that people do not agree with sexual education is cultural education, not just religious values. God has focused on all aspects of people's lives in the Holy Quran, including family life, menstruation, reproduction, and even ejaculation; thus, sexual education can appropriately be presented within the framework of Islamic ideology in Muslim societies (2). Participants also pointed out that sexual education principals as well as sexual educational content are required to be filtered out by Islamic ideology and in line with conservative societies, like Iran. From the scientific point of view, numerous studies have shown that when the principals of comprehensive sex education is provided to the youths, it will not sexually stimulate adolescents $(45,46)$.

Given the cultural situation in Iran, it seems that the provision of a systematic training program can enhance the awareness and self-efficacy of individuals, especially young people. Participants also stated this point and called for the design of relevant government-level policies and the alignment system. Policies can be designed to engage families, schools, universities, and the media, and provide an educational program that fits into Iranian and Islamic culture.

Since the sexual health education cannot easily be imported in the country's educational system (15), Sexual 
Health Education Nessessity Scale that has been extracted from the Iranian context, can be used to assess young single women' beliefs regarding sexual health education and its effects. This questionnaire could explore the necessity of sex education and also the dominant beliefs that may be obstacles for providing a proper sexual health education program. Therefore, working on these beliefs and trying to correct them could help policymakers and health care providers to design an appropriate sexual health education program. In fact, this questionnaire could provide a preliminary situation analysis about designing and providing sexual health education within conservative societies, such as Iran.

The present investigation had a few limitations. Themes identified with sexuality, for example, sex education, are private and personal issues, and they are subjected to various degrees of religious, cultural, moral, and lawful standards and limitations (47). Therefore, a few women favored not to talk about their sexual health education and particularly their sexual encounters. The principal researcher tried to diminish this restriction by setting up affinity and trust. Likewise, on account of religious and legitimate contemplations, it was probable that merely liberally minded and motivated young single women took part in the study, despite the fact that the researcher welcomed all young single women to take part in the investigation. One of the major scientific limitations of this study was lack of males in this study. Designing a similar study on males is suggested because it could provide more details about the effect of gender in sex education and help plan more proper sex education programs. Another scientific limitation was lack of literature review in developing the scale. Although in this study, it was planned to reflect the necessity of sexual health education in the Iranian context, it was preferred to use empirical data only. Also, the participants were single women aged 18-34 years, and a similar study on married couples and other age ranges could enhance the sex education information in the Iranian context. The results of the present study provided primary evidence regarding the assessment of psychometric properties of the Sexual Health Education Necessity Scale. Further investigations in comparable populations are expected to set up more grounded psychometric properties for the scale.

\section{Conclusion}

The findings indicated that most (more than $70 \%$ ) of Iranian women believed that sex education could be useful for them, and sociocultural considerations were highlighted in their statements. The results of the present study provided primary evidence regarding the assessment of psychometric properties of the Sexual Health Education Necessity Scale. This questionnaire could be used for exploring dominant beliefs that may be obstacles for providing sex education in conservative societies. Therefore, correcting these beliefs could help design an appropriate sexual health education program.

\section{Acknwledgments}

This investigation was elicited from the principle investigator's thesis for accepting $\mathrm{PhD}$ degree in Reproductive Health at Faculty of Medical Sciences, Tarbiat Modares University, Tehran, Iran. The authors thank all.

\section{Conflict of Interests}

The authors declare that they have no competing interests.

\section{References}

1. Rahmani A, Merghati-Khoei E, Moghaddam-Banaem L, Zarei F, Montazeri A, Hajizadeh E. Sexuality Research in Iran: A Focus on Methodological and Ethical Considerations. Iran J Public Health. 2015;44(7):979

2. Kotb H. Sexuality in Islam $[\mathrm{PhD}$ diss]: Maimonedes University. Egypt; 2004.

3. Khalajabadi-Farahani F. Norms, attitudes and sexual conduct among female college students in Tehran: implications for reproductive health policy and research. London: London School of Hygiene and Tropical Medicine; 2008.

4.Zangeneh N. A critical view of sexual health education in Iran. http://www.tarshi.net/blog/a-critical-view-of-sexual-health-educationin-iran/; 2013.

5. UNESCO. Review of Policies and Strategies to Implement and Scale Up Sexuality Education in Asia and the Pacific. 2012.

6. Mohammadi MR, Mohammadi K, Farahani-Khalaj-Abadi F, Alikhani $\mathrm{S}$, Zare M, Tehrani FR, et al. Reproductive knowledge, attitudes and behavior among adolescent males in Tehran, Iran. Int Fam Plan Perspec. 2006:35-44.

7. Ferguson E, Cox T. Exploratory factor analysis: A users' guide. Int J Select Assess. 1993;1(2):84-94.

8. Iran-SCo. The overall results of General Population and Housing Census. 2011 [Persian].

9. Organization WH. Youth and health risks. Report by the Secretariat. Sixty-fourth World Health Assembly, document A. 2011;64.

10. UNESCO. What do we mean by "youth"? 2017.

11. Teoretical viewpoints about youth age range. National Youth Organization; 1385; Available from: http://www.aftabir.com/articles/ view/social/youth

12. Mohamadi M, Mohamad K, Khalagabadi-Frahani F, Alikhani S, Zarei M, Ramazani-Tehrani $\mathrm{F}$, et al. Knowledge, attitude and behavior of adolescent boys aged 15 to 18 in Tehran on Reproductive Health. Fertil Infertil J. 2002:237-50.

13. Nasirian M, Doroudi F, Gooya MM, Sedaghat A, Haghdoost AA. Modeling of human immunodeficiency virus modes of transmission in iran. J Res Health Sci. 2012;12(2):81-7.

14. Qaderi S. The third wave of transmission of HIV is increasing. http://wwwKhabaronlineir/news-85500aspx:Available from: URL. 2010.

15. Tavoosi A, Zaferani A, Enzevaei A, Tajik P, Ahmadinezhad Z. Knowledge and attitude towards HIV/AIDS among Iranian students. BMC Public Health. 2004;4(1):17.

16. Bakhshipur A, Bagherian-khosroshahi S. Psychometric properties of revised Eyzenk personality questionnaire: short form. Tabriz: Tabriz University; 2009.

17. Kajula LJ, Darling N, Kaaya SF, De Vries H. Parenting practices and styles associated with adolescent sexual health in Dar es Salaam, Tanzania. AIDS Care. 2016:1-6.

18. Robinson A, Ekwealor FN. Influence of Family Life Education on Sexual Behaviour of in-School Adolescents in Bida Education Zone of Niger State, Nigeria'Eucharia Nchedo Nwosu," Immaculata Nwakaego Akaneme," Danjuma Mohammed "Annah Chinyeaka Uloh-Bethels," Patience Okwudili Nwosu. Res J Biol Sci. 2016;11(2):89-93

19. Negy C, Velezmoro R, Reig-Ferrer A, Smith-Castro V, Livia J. Parental Influence on Their Adult Children's Sexual Values: A MultiNational Comparison Between the United States, Spain, Costa Rica, and Peru. Arch Sex Behav. 2016;45(2):477-89.

20. McCauley KL, Shadur JM, Hoffman EM, MacPherson L, Lejuez C. Adolescent Callous-Unemotional Traits and Parental Knowledge as 
Predictors of Unprotected Sex Among Youth. Behav Modif 2016;40(1-2):70-96.

21. Shirpak K, Chinichian M, Matica-tyndale E, Ardebili H, Pourreza A, Ramezankhani A, et al. A qualitative assessment of the sex education needs of married Iranian women. Sex Cult. 2008;12(13): 150

22. Latifnejad Roudsari R, Javadnoori M, Hasanpour M, Hazavehei SMM, Taghipour A. Socio-cultural challenges to sexual health education for female adolescents in Iran. Iran $\mathrm{J}$ Reprod Med. 2013;11(2):101.

23. Marsman JC, Herold ES. Attitudes toward sex education and values in sex education. Fam Relat. 1986:357-61.

24. Mbonile L, Kayombo EJ. Assessing acceptability of parents/guardians of adolescents towards introduction of sex and reproductive health education in schools at Kinondoni Municipal in Dar es Salaam city. Afr J Public Health. 2008;5(1):26-31.

25. Mosavi SA, Babazadeh R, Najmabadi KM, Shariati M. Assessing Iranian adolescent girls' needs for sexual and reproductive health information. J Adolescent Health. 2014;55(1):107-13.

26. Organization WH. Developing sexual health programmes: A framework for action. Retrieved February 4, 2013. 2010.

27. Katumba R, editor. Kenyan elders defend circumcision. Development Forum; 1990.

28. UNFPA. Using culturally sensitive approaches to achieve universal goals: Lessons from the field. 2004.

29. Johnson RB, Onwuegbuzie AJ. Mixed methods research: A research paradigm whose time has come. Educ Res. 2004;33(7):14.

30. Streubert HJ, Carpenter DR. Qualitative research in nursing: Advancing the humanistic imperative: Lippincott Williams \& Wilkins; 2010.

31. Holloway I, Wheeler S. Qualitative research in nursing and healthcare: Wiley-Blackwell; 2009.

32. Graneheim UH, Lundman B. Qualitative content analysis in nursing research: concepts, procedures and measures to achieve trustworthiness. Nurs Educ Today. 2004;24(2):105-12.

33. Speziale HJS, Streubert HJ, Carpenter DR. Qualitative research in nursing: Advancing the humanistic imperative: Lippincott Williams \& Wilkins; 2010.

34. Haynes SN, Richard D, Kubany ES. Content validity in psychological assessment: A functional approach to concepts and methods. Psychol Assessment. 1995;7(3):238.

35. Waltz C, Bausell R. Nursing research:decision statistics and computer analysis: Philadelphia: Fa Davis Co; 1983.

36. Lawshe $\mathrm{CH}$. A quantitative approach to content validity1. PERS PSYCHOL. 1975;28(4):563-75.

37. Lacasse Y, Godbout C, Series F. Health-related quality of life in obstructive sleep apnoea. Eur Respir J. 2002;19(3):499-503.

38. Cronbach LJ. Coefficient alpha and the internal structure of tests. Psychometrika. 1951;16(3):297-334.

39. Munro BH. Statistical methods for health care research: Lippincott Williams \& Wilkins; 2005.

40. Bay-Cheng LY. The trouble of teen sex: The construction of adolescent sexuality through school-based sexuality education. Sex Educ-Sex Soc Lea. 2003;3(1):61-74.

41. Illes J. Young sexual citizens: reimagining sex education as an essential form of civic engagement. Sex Educ-Sex Soc Lea. 2011;12(5):613-25

42. Rostosky SS, Dekhtyar O, Cupp PK, Anderman EM. Sexual selfconcept and sexual self-efficacy in adolescents: a possible clue to promoting sexual health? J Sex Res. 2008;45(3):277-86.

43. Najarkolaei FR, Niknami S, Shokravi FA, Tavafian SS, Fesharaki MG, Jafari MR. Sexual behavioral abstine HIV/AIDS questionnaire: Validation study of an Iranian questionnaire. J Educ Health Promot. 2014;3(1):10.

44. Merghati Khoei E. Language of love in culture of silence: Iranian women's sexual understandings and sociocultural: School of Public Health and Community Medicine, Faculty of Medicine, University of New South Wales; 2006.

45. Mueller TE, Gavin LE, Kulkarni A. The association between sex education and youth's engagement in sexual intercourse, age at first intercourse, and birth control use at first sex. J Adolescent Health. 2008;42(1):89-96.

46. Kohler PK, Manhart LE, Lafferty WE. Abstinence-only and comprehensive sex education and the initiation of sexual activity and teen pregnancy. J Adolescent Health. 2008;42(4):344-51.
47. Fenton KA, Johnson AM, McManus S, Erens B. Measuring sexua behaviour: methodological challenges in survey research. Sex Transm Infect. 2001;77(2):84-92. 